\title{
Applications of FVCOM
}

This document accompanies a Google Earth file named, "FVCOM Applications.kmz." To get the most out of the use cases presented below, open the accompanying Google Earth file and navigate to the features that are indicated as companions to each use case.

\section{FVCOM Summary}

The Finite-Volume Community Ocean Model (FVCOM) is an oceanographic model that has the capability to create hindcasts and forecasts of oceanographic conditions in coastal and pelagic systems. FVCOM was developed jointly by the Marine Ecosystem Dynamics Modeling Lab at the University of Massachusetts Dartmouth School for Marine Science and Technology (SMAST) and the Woods Hole Oceanographic Institution (WHOI), and has been applied in a number of coastal ocean circulation studies worldwide. Examples of FVCOM data products and their potential uses include the following:

- Data on current velocity that can optimize siting for offshore aquaculture and energy

- Information about ocean temperature and stratification that can improve understanding of migration and feeding patterns of zooplankton, fish, marine mammals and birds

- Models of wave dynamics that can help predict the impact of storms and rising seas on the region's coastlines

- Model outputs that can quantify the stability of various habitats and identify locations that may be important to re-visit more frequently for mapping or characterization work

Examples of how FVCOM has been used are provided below in use case studies, each of which has an accompanying feature in Google Earth. FVCOM has also been used to generate data that have informed ocean planning efforts in the Northeast US, some for which SeaPlan has provided support:

\section{Hindcast Data for Massachusetts and the Gulf of Maine \& the Northeast Ocean Data Portal}

SeaPlan partnered with SMAST, WHOI, and state and federal agencies to estimate past ocean conditions in Northeast US waters to help inform ocean planning efforts. Using a powerful analytic model system called the Northeast Coastal Ocean Forecast System (NECOFS) built on integration of FVCOM and a surface wave model, the team developed 36 years of fine-scale hindcast oceanographic data for Massachusetts coastal waters and the Gulf of Maine Northeast Shelf region. Researchers at SMAST estimated high-resolution hourly increments of surface and bottom temperatures, salinity, stratification, current velocity, and wave heights spanning the years 1978 to 2013.

FVCOM has improved upon other modeling approaches because it was able to account for the region's complex topography and produce hindcasts useful for estimating historical conditions in the absence of observed data. These hindcast data may be used in ocean planning to identify patterns that ocean managers, academia, marine industries, and others may use to better understand ocean dynamics, anticipate data needs, review and site ocean projects, and assess the feasibility of new ocean uses.

To better serve the ocean planning community and make these data products publicly available, SeaPlan supported the inclusion of FVCOM data in Massachusetts and Gulf of Maine waters into the Northeast Ocean Data Portal, an online information resource and decision support tool for ocean planning in the Northeast US. These data are available on the Data Portal and include climatological data products on surface and bottom currents, surface and bottom temperature, and stratification. 
University of South Florida Deepwater Horizon Modeling

Google Earth Companion - FL - Deepwater Horizon Oil Spill Model

Who - University of South Florida

When - 2014

Question/Problem to address - Anecdotal reports from fishermen indicated that reef fish caught in the West Florida Shelf (WFS) region had deformities and other diseases. Could subsurface currents have transported oil from the Deepwater Horizon spill to the WFS region?

Methodological Overview - Scientists added a tracer to the model as a stand-in for oil, using estimated concentrations based on observed conditions in the northern Gulf of Mexico. The model also accounted for mixing by Langmuir circulation and associated waves. Compared tracer patterns to fish sampling locations where lesions and contaminated livers were reported.

FVCOM Application - The model used in this project was the West Florida Coastal Ocean Model (WFCOM), which consists of FVCOM nested in the Hybrid Coordinate Ocean Model (HYCOM).

Summary of Findings/Outcomes - Locations of contaminated fish are consistent with modeled tracer locations, suggesting the possibility that hydrocarbons "may have permeated much of the WFS."

Link to original source/paper - http://www.sciencedirect.com/science/article/pii/S0967064514000356

Great Lakes Ice Cover Modeling

Google Earth Companion - Great Lakes Simulated Ice Cover

Who - NOAA

When - Ongoing

Question/Problem to address - GLOFS (Great Lakes Operational Forecast System) is designed to improve predictions of water levels, water currents, and water temperatures in the Great Lakes for the purpose of maximizing safe operations and economic activities throughout the Lakes. The next generation of GLOFS incorporates FVCOM-Ice, which improves and refines the system by modeling sea ice processes in the Great Lakes. The application can model ice thickness, extent, and thermal structure.

Methodological Overview - Since this is the first known application of the ice model on freshwater lakes, the current focus is on comparing model results to observed data and results from older models.

FVCOM Application - An FVCOM unstructured grid model was implemented for the Great Lakes. An ice module comes with FVCOM as a sub-module. The ice module is based on CICE (Los Alamos Sea Ice Model), but can be adapted to the unstructured grid in the study area.

Summary of Findings/Outcomes - FVCOM-Ice outperformed ICEPOM (ice model based on the Princetown Oceanographic Model) in Lake Erie simulations. The model continues to undergo refinements and further model-data comparisons are being conducted.

Link to original source/paper - https://www.glerl.noaa.gov/res/Programs/ipemf/ice.html 


\section{Use Case Studies}

San Francisco Bay Operational Forecast System

Google Earth Companion - San Francisco Bay Operational Forecast System Grid

Who - NOAA

When - Ongoing

Question/Problem to address - SFBOFS provides nowcast and forecast data on water levels, currents, water temperature, and salinity for San Francisco Bay and the San Francisco Bay entrance. The purpose of this model is to help U.S. port authorities and mariners to traverse these areas safely and efficiently.

Methodological Overview - Predictions rely on observed data or forecasts from large-scale numerical models, including the North American Mesoscale weather prediction model from the National Weather Service and the Global Operational Real-Time Ocean Forecast System from the National Center for Environmental Prediction.

FVCOM Application - SFBOFS uses FVCOM as its core ocean prediction model.

Link to original source/paper - https://tidesandcurrents.noaa.gov/ofs/sfbofs/sfbofs info.html

\section{Olympic Sailing Tidal Predictions}

\section{Google Earth Companion - 2008 Olympic Tides}

Who - UMass Dartmouth, North China Sea Environmental Monitoring Center for the State Oceanic Administration

When - 2008

Question/Problem to address - This project predicted the tidal elevation and currents in Jiaozhou Bay and the Yellow Sea to prediction conditions at the 2008 Olympic sailing site

Methodological Overview - Model was tested by comparing results from the hindcast with data from tidal gauges and shipboard current measurements at the site.

FVCOM Application - FVCOM was used to develop hourly current predictions

Summary of Findings/Outcomes - Observations validated the model. Tidal elevation and currents were both available on an hourly basis.

Link to original source/paper - http://fvcom.smast.umassd.edu/2014/01/13/7-outreach-olympic-sailing/ 


\section{Use Case Studies}

Scituate 2010 Nor'easter Inundation Modeling

Google Earth Companion - Scituate Inundation Modeling

VIBRANT ECONOMIES - HEALTHY OCEANS

Who - UMass Dartmouth, WHOI

When - 2013

Question/Problem to address - Scituate MA was selected to be the first coastal New England town to be selected by the National Weather Service as a pilot site to establish a coastal inundation prediction model system that could later be adapted to other regional locations. This project tested the Scituate FVCOM model to examine whether model resolution and other model components on predicted flooding, using the December 2010 nor'easter and its inundation effects as the simulated event.

Methodological Overview - Hindcasts were made using two different resolution model grids. In one set of simulations, wave-current interaction data were included, while in the second set of simulations they were not.

FVCOM Application - Researchers developed the Northeast Coastal Ocean Forecast System (NECOFs) around FVCOM to produce 3-day forecasts of oceanographic conditions. A site-specific FVCOM model was developed for Scituate. This model was a high-resolution coastal inundation forecast model.

Summary of Findings/Outcomes - Including wave-current interactions in the model produced results that were closer to the observed storm surge.

Link to original source/paper - http://onlinelibrary.wiley.com/doi/10.1002/2013JC008862/full 